\title{
Ironía y exilio en la obra reciente de Federico Patán
}

\author{
Nair María ANAYA FERREIRA \\ Universidad Nacional Autónoma de México
}

\begin{abstract}
El propósito de este artículo es explorar la noción de exilio en la obra reciente de Federico Patán y la forma en que ésta adquiere un tinte universal cuando se le considera como un elemento resultante de la modernidad. Expongo que incluso en su obra autobiográfica Una infancia llamada exilio existe un trasfondo irónico que se ha convertido en un rasgo distintivo del autor y que conlleva una crítica constante de la falta de un anclaje ético y espiritual de los individuos de la segunda mitad del siglo XX y los primeros años del XXI, crítica que constituye el eje central de su novela más reciente, ¿Y el paraíso?
\end{abstract}

PALABRAS ClAVE: Federico Patán, narrativa mexicana, ironía, exilio, exilio español, literatura hispanomexicana, modernidad.

The aim of this article is to explore the notion of exile in Federico Patán's most recent works, and the way in which it acquires a sense of universality when considered as a consequence of modernity. I argue that even his autobiography, Una infancia llamada exilio, is sustained by an underlying irony which has become the author's distinctive feature. This irony embodies a constant critique of the individuals' lack of ethical and spiritual values during the second half of the twentieth century and the early years of the twenty first, critique which constitutes the central theme of his most recent novel ¿Y el paraíso?

KEywords: Federico Patán, Mexican narrative, irony, exile, Spanish exile, Spanish-Mexican literature, modernity.

En décadas recientes, los estudios sobre identidad y memoria se han concentrado en las repercusiones de las migraciones diaspóricas que ocurrieron principalmente durante los siglos XIX y XX. En mayor o menor grado, dichas migraciones tienen su origen en un acontecimiento traumático que muchas veces llevó al exterminio de millones de personas (pienso, por ejemplo, en el fenómeno de la esclavitud o el Holocausto) o en 


\section{IRONÍA Y EXILIO EN LA OBRA RECIENTE DE FEDERICO PATÁN}

guerras civiles que expulsaron a comunidades enteras de su lugar de residencia. Tal es el caso del exilio español en México, suceso que, bien sabemos, transformó la vida y cultura de nuestro país desde finales de la década de los treintas del siglo pasado. La (re)creación de las experiencias vividas, ya sea en géneros poéticos, ficcionales o autobiográficos, es una de las formas de rescatar un pasado que, muchas veces, corre peligro de perderse en la oscuridad de las historias "oficiales" de dichos eventos. Más que eso, constituye un vehículo valioso para que lectores posteriores puedan leer, conocer y, de ser posible, aprehender aquellos elementos intangibles que se pierden en la supuesta objetividad y exactitud de la historia y que, ciertamente, están mediados por una subjetividad que obliga a redimensionar la naturaleza de los hechos.

Sobre el exilio español en México hay una abundante bibliografía, desde la obracreativa y autobiográfica de sus principales representantes hasta escritos críticos que han estudiado la importancia de dichas figuras en la vida cultural de México. Los temas que salen a la superficie comparten, más allá de las especificidades propias, muchos de los rasgos que ahora se exploran teóricamente en campos como los estudios poscoloniales, de la memoria y de la identidad: una sensación de desarraigo no sólo geográfico, sino también lingüístico, psicológico, cultural y, se podría decir, espiritual; una conciencia de no tener identidad fija, única e inamovible —en el sentido decimonónico-, sino, al contrario, una identidad en transformación constante que, sin embargo, busca también un ancla donde establecerse; una percepción sagaz de los cambios ocurridos en el entorno geográfico y social, así como de las relaciones interpersonales; una relación especial con el pasado, determinada por la convicción de que el acto de rescatarlo creativamente conlleva también una especie de recuperación moral mediante la cual se sientan las bases para el futuro. En Los poetas hispanomexicanos. Estudio y antología (2012), Enrique López Aguilar identifica dos generaciones iniciales entre aquellos que tuvieron que dejar España a raíz de la guerra civil. En la primera están incluidos intelectuales que llegaron a México ya formados y que ahora son conocidos por haber dejado un importante legado en todas las áreas del conocimiento: Adolfo Sánchez Vázquez, Eduardo Nicol, Joaquín Xirau, José Gaos. La segunda, más cercana a nosotros, está constituida por aquellos que llegaron a México entre los dos y los catorce años de edad (nacidos mayormente en la década de los treintas) y que son "hijos de quienes participaron en la Guerra civil española y optaron por la emigración forzada después de la derrota de la República" (López Aguilar: XVIII). Esta generación, a la cual se ha denominado generación "nepantla", "fronteriza" o "transterrada" (López Aguilar: 7-9), fue, como dice Angelina-Huberman en El canto del peregrino, una generación ambigua que padeció una especie de pérdida de nacionalidad y que, si no fue completamente rechazada por la sociedad mexicana, sí experimentó algunas formas de marginación. Sin embargo, autores como Arturo Souto, Gerardo Deniz, Manuel Durán, Jomi García Ascot, Nuria Parés, Angelina Muñiz y Federico Patán, al abarcar "las dos nacionalidades que los une y caracteriza" y con el "deseo de trascender fusionando" (Muñiz-Huberman: 156, 69), constituyen más bien la generación "hispanomexicana" — término acuñado por Arturo Souto—y comparten ciertos rasgos en común, en especial, 
un tono nostálgico, una creciente interiorización y subjetivación creativa, y el uso consciente de varios registros de la lengua que los distingue de los autores mexicanos de la misma generación.

El propósito del presente ensayo será explorar cómo la noción de exilio (tanto geográfico como interno) está presente en la obra reciente de Federico Patán y adquiere una dimensión irónica tanto en la recreación autobiográfica de su niñez - Una infancia llamada exilio (2010) — como en la novela ¿Y el paraíso? (2012). Mi argumento será que, como autor hispanomexicano, Patán ha trasladado a sus obras la expulsión del paraíso que, para críticos como Angelina Muñiz, constituye el rasgo subyacente de toda reflexión sobre el exilio. La contraposición de estas obras permitirá explorar el proceso de identificación por parte de Patán con la realidad mexicana, desde los primeros momentos de una niñez en los que la familia española fue echando raíces en México, hasta el sentido de desilusión y la distancia narrativa que distingue la última novela. Si bien los protagonistas de la obra de Patán han sido descritos como personajes que encarnan exilios internos de diversos tipos, es importante destacar que éstos son personajes mexicanos insertos en la realidad de nuestro país. El exilio interno de estas figuras surge de la condición inherente de Federico Patán como exilado, así como de su percepción de la falta de un anclaje ético y espiritual de los individuos de la segunda mitad del siglo XX y los primeros años del XXI, sean éstos mexicanos o no. En este sentido, sus protagonistas viven siempre en una situación de otredad incluso consigo mismos y esto es lo que hace la obra de Patán tan importante dentro del panorama narrativo de México y el mundo hispanohablante. El hilo subyacente en su obra cuentística y novelística es una distancia crítica con respecto a dicha condición de exilio que ha ido llevando al autor al empleo de una ironía cada vez más mordaz que alcanza su culminación en la novela de 2012 y que, ciertamente, como exploraré a continuación, se encuentra también presente en su obra autobiográfica.

Una infancia llamada exilio ofrece una visión conmovedora y única de los primeros años en México de una familia migrante a través de una remembranza lúcida, en ocasiones irónica, en otras melancólica, de un proceso de adaptación que no por estar limitado a una dimensión personal o familiar deja de ser pertinente para una reflexión más amplia no sólo sobre el exilio en general sino también sobre la formación sociocultural de las llamadas identidades diaspóricas. En su carácter de narración autobiográfica, Una infancia llamada exilio está marcada por la subjetividad. Dicha característica es, de suyo, el rasgo distintivo de la autobiografía, pero en el caso de esta obra, el énfasis en la subjetividad constituye la estrategia que agrega una dimensión irónica y autorreflexiva a la vez.

Desde los epígrafes que enmarcan la narración, Patán introduce los elementos paradójicos con los que reconstruirá sus años de infancia. Un verso de Juan Bañuelos, una frase de Tomás Segovia y un párrafo de Donald M. Lowe hacen hincapié en que toda reconstrucción narrativa de la vida propia, en especial de la infancia, tiene que abrirse camino a través de una densa nube que empaña la búsqueda objetiva del pasado. Y no puede ser de otra manera pues, como dice Lowe en el párrafo elegido por 


\section{$118 \square$ IRONÍA Y EXILIO EN LA OBRA RECIENTE DE FEDERICO PATÁN}

Patán, "No hay pasado en sí mismo. Se ha perdido para siempre. Mas cada presente simboliza un pasado en sus propios términos. Por tanto, un pasado es la retrospección intencional por un presente". Que Patán haya elegido a este pensador chino-estadounidense no es gratuito, pues la obra de este último se concentró en estudiar la historia de la percepción en el mundo moderno, en especial, la forma en que las jerarquías variantes de los sentidos, en conjunción con las prácticas sociales y los medios de comunicación, determinan la construcción de un sentido de identidad personal.

Patán deja implícito desde el título y el capitulado de su obra que los recuerdos siempre se ven afectados por elementos externos que dictan la configuración de una narración escrita sobre la infancia. Como establece Mark Freeman, lo que es "mío" siempre está impregnado de la otredad, ya que el proceso de recordar el pasado personal siempre ocurre en y a través de la lengua, la cultura y la historia y, de este modo, comparte fuentes que se encuentran fuera del perímetro del yo (Freeman: 274). En este caso, dicha otredad toma la forma de un exilio que, para Patán, es tanto físico como metafórico.

Si la noción de exilio evoca nociones de desplazamiento y desarraigo, el hecho de que infancia y exilio sean vistos casi como sinónimos profundiza de entrada el sentido de otredad y fragmentación que permea el texto comentado aquí. De hecho, los episodios narrados en el primer capítulo, "Fragmentos", sirven como preámbulo tanto de la dinámica como del tono que caracterizarán el resto del volumen, el cual, por otra parte, ofrece una cronología centrada en un sólo lugar geográfico - la ciudad ¿pueblo en ese entonces? de Perote, en el estado de Veracruz- y en los sitios por los que transcurrió la infancia de Patán, en especial, la escuela y el restaurante administrado por su padre. Tres anécdotas sobresalen en este capítulo, en especial porque articulan de entrada el tema central del libro: la reflexión sobre una identidad dual, mexicana y española, marcada por un acontecimiento histórico mayor - la Guerra civil española- y definida por las características de un entorno provinciano en el México de la década de los cuarentas. La primera relata cómo el chofer de un camión de redilas recoge en Chihuahua a un niño pequeño que camina por una calle larga y polvosa en busca de la abuela que vive, exilada, en Francia. La segunda recuerda cómo un bebé de brazos levanta el puño derecho — saludo republicano- frente al oficial francés que revisaba los documentos de ingreso de los refugiados. La tercera muestra a un niño un poco mayor que juega con un martillito de madera al tiempo que entona, de modo un tanto inconsciente, el himno nacional de México, ante la sorpresa y risas de quienes lo rodean. Si el recuento de los tres eventos está enmarcado por los comentarios de los adultos cabe hacer las siguientes preguntas: ¿cómo es posible narrar las memorias de infancia si no es mediante los recuerdos de alguien más o con la ayuda de objetos documentales como fotografías, cartas o recortes de periódico?, ¿cuál es la veracidad de dichas remembranzas, si éstas llegan de forma indirecta? El mismo Patán ofrece una respuesta: "Quién cuenta y el modo de hacerlo determinan el grado de verosimilitud. En buena medida esto se une a la literatura. La anécdota narrada puede ser un cuento folclórico o permanecer como trozo de mis memorias" (34). En Una 
infancia llamada exilio la reconstrucción de los fragmentos, aunado al grado de verosimilitud de lo narrado demuestran por qué la intermediación conjunta de memoria y narración, "lejos de ocultar la realidad, más bien la revela, y a través de esta revelación, la redefine" (Freeman: 276).

De esta forma, Una infancia llamada exilio logra exponer no sólo la relación de incidentes personales que configuran al individuo llamado Federico Patán, sino también conjuntar, por un lado, la vida azarosa de sus padres durante su proceso de adaptación y supervivencia en tierras extrañas y, por el otro, las costumbres y los hábitos más bien conservadores de una pequeña ciudad de la provincia mexicana en vías de modernización. De los padres conocemos su separación en los campos de refugiados y el viaje a bordo del Mexique en julio de 1939; la actitud de tranquila inocencia que caracterizó siempre a la madre (y que Federico cree haber heredado), así como su silenciosa dedicación y trabajo por el bienestar de la familia; la severidad y los duros castigos impuestos por el padre, su aversión al lenguaje soez, pero también el cariño mostrado en el único viaje que hicieron juntos a las playas de Veracruz y su afición a la lectura, la pintura y la fotografía; la diferencia de intereses entre ellos, que los llevó a vivir una vida cotidiana que "se limitaba a los intercambios de la convivencia" (210) pero en la que, sin embargo, no hubo pleitos ni enojos. La narración de esa vida cotidiana poco deja ver el sufrimiento callado que deben haber padecido ante la separación forzosa de Sonia, la hija mayor, quien fue enviada a la Unión Soviética en 1938 para ponerla a salvo de la guerra, pero con quien sólo pudieron volver a reunirse hasta 1957, ¡casi veinte años después! La infancia de Patán encarna, entonces, uno de los rasgos fundamentales de los autores del exilio español. En palabras de Silvia Jofresa Marquès, en su estudio introductorio a El canto del peregrino:

La palabra se convierte en la única tierra del exiliado, el único lugar donde puede construirse una identidad. Tal sentimiento de pertinencia se ve intensificado por el peculiar hecho de que la memoria que poseen [los escritores hispanomexicanos] ha sido fruto de un relato. Su exilio les fue dejado en herencia mediante la palabra... En otras palabras, es una generación acostumbrada a que el pasado les sea contado. Escuchar los relatos es su forma de vivir la historia. Su recuerdo, pues, va a estar constituido por la narración (apud. Muñiz-Huberman: 11).

La recreación de la atmósfera de Perote, así como su gradual transformación, son inseparables de la narración misma de la vida de Patán. Se percibe un sentido de nostalgia frente a la pérdida del "vivir pausado de aquella gente provinciana, [de] lo libre de tensiones que pasaban los días" (31). Ahí, anota:

[...] vi matar reses, cochinos y pollos; fabricar embutidos; cocinar chicharrón y carnitas; hacer leña; arar la tierra, sembrarla y recoger la cosecha; construir casas; montar los juegos de una feria; asistir a la descarga de camiones en el mercado; observar la toma de agua por parte de trenes en la lejana estación; la fabricación de tablones en el aserradero; el tráfago del restaurante cuando llegaba un autobús de ADO (50). 


\title{
$120 \square$ IRONÍA Y EXILIO EN LA OBRA RECIENTE DE FEDERICO PATÁN
}

Un quinto le alcanzaba para comprar galletas marías o de animalitos y disfrutaba las cuartetas recitadas en su honor por el hombre vestido de blanco y con sombrero de paja por dos o cinco centavos. En general, las remembranzas parecen estar imbuidas por una sensación de inocencia y nostalgia a la que Patán hace alusión en numerosas ocasiones:

\begin{abstract}
Mi infancia está llena de elementos que fueron desapareciendo de la vida cotidiana: la estufa de leña o carbón (y más tarde la de petróleo), el manguillo con plumilla, el zurcido de calcetines, las planchas primitivas, los colchones de borra, la entrega de leche a domicilio en recipientes de metal, el remendado de zapatos, el uso de papel de estraza en las tiendas, para envolver las compras del cliente (138-139).
\end{abstract}

Una infancia llamada exilio narra, entonces, una doble expulsión del paraíso: la expulsión de la España republicana narrada por los padres, y la de una infancia que, además de atestiguar la entrada en la modernidad de una región rural que pierde parte de su esencia, también concluye en otra migración: la mudanza de la familia a la ciudad de México. (Hay también un exilio intermedio, cuando por necesidad fue enviado por los padres a Veracruz en 1949.)

Uno de los principales rasgos distintivos de la literatura poscolonial anglófona es la brecha que se forma, en primer lugar, cuando el idioma inglés carece de los términos necesarios para nombrar los objetos, frutos, árboles del entorno colonizado y, en segundo lugar, cuando al ser empleado por los individuos colonizados el idioma adquiere nuevos significados y genera una fricción que produce un sentido de alteridad. Algo similar ocurre en la percepción lingüística que subyace Una infancia llamada exilio, la cual, en cierta forma, es fundamental para la conformación identitaria del autor. $\mathrm{Si}$, como afirman Carmen Curcó y Maite Ezcurdia, "[d]urante el periodo de adquisición del lenguaje no solamente tiene lugar la conformación del sistema cognoscitivo determinado por la sintaxis y la semántica de la lengua materna. Se produce, a la par, la apropiación de las prácticas discursivas en las cuales esta lengua se inserta" (15), la narración de Patán se inserta en los intersticios que se abren entre el hogar (español peninsular) y el ambiente exterior (español mexicano). Esta característica — que constituye, de hecho, el rasgo distintivo de la obra general de Patán y de otros escritores hispanomexicanos- subyace el relato autobiográfico de forma sutil y perspicaz a la vez. Al desembarcar en Veracruz, la extrañeza de la madre ante los vendedores que ofrecen algo tan absurdo como "mangos" se convierte en asombro al descubrir que no es el asa de un utensilio sino la carnosa fruta típica de este país. Algunos homónimos (tortilla, por ejemplo) producen situaciones cómicas, pero otras expresiones menos refinadas apuntan ya a una alteridad claramente identificada, desde el "güerito" que distinguía a Patán, niño de "pantalón corto y rizos abundantes y rubios" (2010: 12), de los campesinos de la región, hasta el más agresivo "gachupines" con que la maestra se refirió a "los infames españoles [que] habían destrozado las culturas nativas" (136) y que produjo en Federico una justificada confusión histórica. El primero, deduce Patán, "establecía 
diferencias de origen... nunca me lo aplicaron sino personas muy contrastantes con mi tipo de apariencia" (45); el segundo, más peligroso, fue quizá el causante el misterioso incendio del restaurante, y acompañó a Federico en varias ocasiones:

\begin{abstract}
A lo largo de mi vida jamás faltaron los obcecados con un nacionalismo primario que, por lo general, me enviaban de regreso a España, acompañando la invitación con majaderías. De adolescente, varios de esos ataques me sacudieron hondo; luego, la madurez me ha dado paciencia con los ex abruptos de personas escasamente pensantes. Los fundamentalismos no tienen como una de sus características el razonamiento, aunque quienes los obedecen supongan estar racionalizando algo que es meramente visceral. Es de confesar que, gracias al paso del tiempo, esas actitudes se han atenuado, al menos en los estratos sociales que frecuento; ahora, todo se limita a la pregunta ocasional de algún taxista: Usted no es mexicano ¿verdad? Pero no hay reproche en ella, sino curiosidad (136-137).
\end{abstract}

Las memorias delimitan, entonces, la caracterización de Patán a partir de un sutil, pero siempre presente sentido de otredad.

No podían faltar en el libro dos de los elementos que subyacen el resto de su obra creativa: su pasión por el cine y la literatura. A través de las alusiones a diversas películas y lecturas es posible no sólo hacer una reconstrucción del ambiente cultural de los cuarentas sino, también, a partir de las opiniones vertidas sobre tal o cual película, sobre un libro u otro, intuir cómo se fue gestando la sensibilidad del Federico persona y del Federico escritor. Del recuerdo de Tarzán de Johnny Weissmüller, pasando por la lacrimógena Jesús de Nazareth y algún melodrama argentino o mexicano, así como la lectura de cómics de Memín o Batman, y la obligada Corazón diario de un niño, surge el ojo crítico de Patán para reflexionar sobre su falta de un sentimiento religioso - sustentado también en las creencias familiares-, sobre la conciencia de la muerte, la fugacidad de la vida y la necesidad de capturar o disfrutar el instante. El comentario hecho sobre Tarzán como figura arquetípica — más allá de sus rasgos colonialistasdice mucho acerca de los valores literarios y personales de Patán: "capaz de sobrevivencia en un medio hostil, con base en la destreza física y en la agilidad mental; dueño de un sentido de la justicia eficaz, si bien primario; dotado de lealtad, honradez, buenos sentimientos; solitario y autosuficiente" (61). Llevadas a otro nivel, estas características dotan de un significado mayor, muchas veces irónico, el interés literario de Patán por los pormenores de la vida cotidiana.

Las memorias, a pesar de estar centradas en su infancia en Perote, y a través del entretejimiento de sucesos en diferentes periodos de su vida, nos introducen no sólo a la vida de Federico Patán, sino a muchos de los temas y estrategias de su obra creativa. Más allá del intimismo que subyace la autobiografía, Una infancia llamada exilio cumple también con una función metanarrativa que la vincula con el resto de la narrativa de Patán. Por ejemplo, después de una función de magia de Fu-Manchú en el teatro Arbeu, en uno de los viajes a la ciudad de México que tanto le fascinaban, Patán se entera por una explicación de su padre "que todo mago es un fabricante de trucos y que 
en la calidad del engaño está la virtud del artista. Por tanto, y a partir de allí, mi intención (a menudo fallida) fue descubrir el mecanismo de la fantasía". Consciente de su función como escritor, Federico agrega: "Lo mismo ocurre con la narrativa. Leemos una novela sabiendo que es una fabricación, pero quedamos mesmerizados cuando el engaño no descubre sus costuras o cuesta mucho descubrírselas. En cambio, una novela patosa desanima de seguir adelante con ella. ¿Para qué, si su ineptitud es palpable desde el comienzo?" (134). Tal fue el caso de su lectura de Mujercitas y Hombrecitos, que "no pasaron de la primera lectura. Les faltaba, pensé en ese entonces, vigor narrativo y les sobraba sentimentalismo" (180).

La falta de sentimentalismo y la perfección en las costuras de su narrativa son, ciertamente, dos de los rasgos fundamentales de la obra de Patán que definen la estructura de Una infancia llamada exilio y del resto de su obra creativa. Es importante destacar dichas características por la naturaleza misma de la temática que subyace la mayoría de sus escritos. Patán ha creado algo que podríamos llamar una "estética de lo cotidiano", la cual es construida por una sutil ironía que conduce a conclusiones insólitas que obligan al lector a cuestionarse la naturaleza misma de la realidad. Sin embargo, la atmósfera intimista de sus narraciones y su minuciosa creación de espacios (claramente mexicanos, por cierto) da lugar a una paradoja que hace de Patán un escritor especial en el medio literario de nuestro país: la mexicana cotidianidad de sus tramas es producto, como asevera Angelina Muñiz, de "una sutil matización del exilio" (162). Al mismo tiempo, sin embargo, el hecho de no haber crecido dentro del ámbito "institucional" de la mayoría de los exiliados españoles (por ejemplo, no haber asistido a escuelas como el Colegio Madrid, el Vives o la Academia Hispano-Mexicana, el haber estudiado la carrera de Letras Inglesas en lugar de la de Letras Hispánicas como la mayoría de los autores hispanomexicanos, o bien haber empezado a escribir tardíamente) lo convierte, en palabras de López Aguilar, en "bastante 'excéntrico"' (XXVIII).

La conciencia del exilio permea, con certeza, la obra de Patán. La infancia en Perote y su amistad con Cándido y Alberto despertaron la sensación de ser distinto de ellos:

[...] resulta que yo no era de por los rumbos donde vivía. Cándido podía extender la memoria hacia atrás y todos sus antecedentes eran de la zona. Lo mismo con Alberto. Yo, sin embargo, había llegado de Francia en un barco llamado Mexique. A Francia había llegado de Barcelona y a Barcelona de Gijón, donde nací. Quizá no presté demasiada atención al tema en aquellos momentos, pero deduzco que por entonces me fue naciendo en la cabeza el exilio consciente, que es el único con existencia verdadera (209).

En otros escritos, como en "Invitación a un exilio" citado por López Aguilar, Patán deja de manifiesto también la ambigua identidad que surge no sólo de saber que siempre llevará consigo la influencia de su pasado español sino también que, conforme su arte fue madurando, "mis otros libros dejaron atrás al exilio como materia de comentario y prefirieron adentrarse en los terrenos acaso predecibles de las angustias existenciales (con atención especial a la muerte en uno de los periodos) y 
los recovecos amorosos y las perplejidades ante un mundo difícil de comprender". Pero, como si dicha ambigüedad no fuera poco, la elección de la literatura inglesa como modo de vida y como sustento intertextual de su propia narrativa agrega un elemento más a la "excentricidad" de su vocación: "Pienso que lo anterior [la influencia hispana y la inglesa] expresa mi condición anfibia en cuanto al idioma, lo que a su vez expresa una condición de biculturalismo y, por ende, mi origen en el exilio" (apud. López Aguilar: 84-85).

Desde este punto de vista, la obra de Federico Patán se inserta en el marco de autores para quienes el exilio puede ser considerado, según Angelina Muñiz, como una estética de la modernidad (87). Si establecemos una conexión entre la obra autobiográfica y la narrativa de Patán, en especial su novela más reciente ¿Y el paraíso?, podemos partir de tres elementos que constituyen su propia poética. Una infancia llamada exilio tiene un hilo conductor subyacente que es un sentido de inocencia tanto en su acepción de una forma candorosa y sencilla de ver y actuar la vida, como en el sentido más ético de una integridad existencial que se ve afectada por los avatares de la vida. La narración de la infancia y juventud temprana destaca el proceso de adaptación a un nuevo entorno desde la perspectiva del emigrado, pero no queda ahí. Los cimientos estructurales de la autobiografía están colocados con la misma precisión y minuciosidad del resto de la obra de Patán, rasgo que Alfredo Pavón destaca en el "Dossier" publicado en la Revista de Literatura Mexicana Contemporánea. Los cuentos y novelas de Federico obedecen a un diseño previo en el que lo cotidiano oculta preocupaciones mayores sobre la naturaleza humana. Como escribe Pavón: "No extrañaría, incluso, que, diariamente, anotara, en íntima agenda, los detalles de la vida cotidiana susceptibles de convertirse, más tarde, en piezas de alto nivel estético" (2008: I). Así, en la autobiografía, la cotidianidad relatada y la creciente toma de conciencia del narrador va generando la ironía con la que concluye el libro y que la vincula con el resto de la narrativa del autor, en especial su novela más reciente: ¿Y el paraíso?

Una infancia llamada exilio concluye con la nostalgia infantil de tener que abandonar, de un día para otro, los tesoros personales en el terreno baldío frente a la casa: los libros y las historietas que tanto deleitaban a Federico niño. Salvo la posibilidad de rescatar Corazón diario de un niño y Pinocho, lo demás se convierte en el botín de los azorados amigos. La razón de tal desasosiego infantil parece ser un gran golpe de suerte para la familia. El padre se ha sacado la lotería y el monto recibido, treinta mil pesos de aquel entonces, permitían probar fortuna en la capital. En unos cuantos días, la vida de Federico, la que el lector fue apreciando en todo detalle, dio una voltereta fenomenal. Un acontecimiento de estas dimensiones podría recibir un tratamiento lleno de interjecciones que mostraran gran regocijo y beneplácito ante las expectativas que se abrían. Sin embargo, con la sobriedad que caracteriza al autor, y vista desde los ojos infantiles, la perspectiva de la mudanza conlleva trabajo extra para la madre y una incertidumbre que, en la última frase de la obra, adquiere una dimensión irónica, que apunta a lo trágico y que vincula a esta autobiografía con el resto de la obra narrativa del autor. El claro contraste entre la visión infantil y la intromisión del narrador adulto 


\section{IRONÍA Y EXILIO EN LA OBRA RECIENTE DE FEDERICO PATÁN}

anuncia un tema recurrente en la obra de Patán que Angelina Muñiz ha identificado con sutileza:

La ficción [de Patán] envuelve a la realidad de una manera cómoda, por medio de sorpresas naturales, de lenguaje tranquilo y sugerente, de añoranzas obsesivas, de misterios equilibrados. Hasta que, de pronto, salta, sin perder armonía la desolación, el engaño, la muerte. Una frase a medias o una oración final pueden representar la trasgresión irreversible, la exhibición del artificio o la confirmación de lo anormal como norma (162).

Tal es el caso de la conclusión de Una infancia llamada exilio. El ritmo aparentemente pausado de la narración de la vida cotidiana en Perote se convierte en un suspenso existencial ante el horizonte de un futuro en la capital del país, ciudad que tan atractiva había resultado para toda la familia durante los periodos vacacionales. Una vez más, la percepción de los adultos permea la visión infantil del narrador, pero, al mismo tiempo, el narrador adulto emite la última palabra: "No recuerdo las despedidas. No sé cuál fue la reacción de Jaime, Consuelo y Gonzalo. Ignoro lo que pensaron Alberto y compañía. De pronto, ya estaba en el autobús. De pronto, la excitación de lo que venía fue ocupando mi persona. Según los testimonios de mis mayores, íbamos al paraíso. Ilusos" (220).

"Ilusos". Quizá no haya un término mejor para describir la preocupación temática y existencial que domina la obra de Patán. En el contexto de la autobiografía, gracias a las prolepsis, sabemos que, después de todo, Federico se convirtió en escritor; que tiene una familia estable y, podríamos decir, feliz; que ha disfrutado a sus hijos y nietos. Sabemos también que ese grado de prosperidad fue alcanzado a base de mucho esfuerzo y una dosis de sufrimiento. "Ilusos", entonces, encarna el sutil escepticismo existencial y la ironía fina que subyacen la autobiografía misma y el resto de la obra del autor. Dos palabras del último párrafo, "paraíso" e "ilusos", vinculan Una infancia llamada exilio con la novela más reciente de Patán ¿Y el paraíso?, publicada en 2012, en la que el autor juega despiadadamente con las expectativas del lector.

Lo que hemos identificado como la "estética de lo cotidiano" conduce, en esta novela, a un giro de tuerca aun más acentuado que en novelas anteriores, en parte, quizá, porque el protagonista — Gastón — tiene la intención inicial de escapar de la rutina, sin saber que dicha decisión lo llevará a la muerte. Patán emplea algunas de las estrategias narrativas que lo distinguen: la novela tiene, con certeza, un diseño en el que ningún elemento de la trama queda al azar; el desencanto de los protagonistas con las elecciones realizadas en su vida pulsa latente a lo largo de los acontecimientos; la sensación permanente de un exilio interno actúa en contrapunto a la necesidad de viajar a la playa, en búsqueda de algún tipo de epifanía; hay una descripción minuciosa de los hábitos de los personajes, así como del entorno cotidiano que los rodea; los protagonistas tienen una conciencia ineludible de que hasta la vida más sosa encuentra ecos en la literatura o la cinematografía (o viceversa) de modo tal que la novela, en un nivel, se inscribe en la dimensión metatextual mediante la cual Patán 
cuestiona permanentemente no sólo la relación entre realidad y literatura, sino, también, la adecuación de los géneros literarios al tipo de circunstancia que conforma una obra de arte.

¿Y el paraíso? es un palimpsesto en el que se entretejen con sutileza elementos de narración costumbrista, comedia de enredos, diálogo filosófico y parodia de thriller, el cual crea el suspenso subyacente que se percibe desde los primeros párrafos y otorga una dosis de humor negro que crea constantes ambigüedades éticas a lo largo de la narración. La carta con la que inicia la novela poco deja vislumbrar sobre lo que ocurrirá más adelante, pero delinea el carácter y la duda existencial del protagonista y anuncia las preguntas sugeridas en el título: ¿existe la felicidad?, ¿cómo se alcanza el paraíso? A partir de éstas, Patán introduce un juego de azares y coincidencias, que convierten al ser humano en una especie de muñeco del destino, a pesar de su deseo constante de asumir el control de su vida. Es en este punto donde Patán muestra una actitud escéptica, que borda en el pesimismo, sobre las posibilidades reales de cualquier persona de alcanzar una vida plena. Y es aquí también donde la ironía desempeña un papel fundamental: no es gratuito, en este sentido, que el protagonista, Gastón - hombre solitario cuyo horizonte vital se ve reducido a un pequeño departamento que da a un patio gris y minúsculo en el que imagina vivir aventuras diversas-, sea incapaz de enfrentar verdaderamente los retos de la vida y tome decisiones fuera de tiempo, escudado en el azar. Luego entonces, Patán inserta un elemento todavía más determinante en dicha búsqueda de felicidad: ¿hasta qué punto puede un ser humano ejercer, en verdad, su libre albedrío?

Como estrategia narrativa Patán emplea un narrador heterodiegético que ejerce un alto grado de focalización en los protagonistas. Entra y sale de la conciencia de éstos de forma tal que genera ambigüedad en muchos de los juicios y opiniones emitidos sobre los sucesos. ¿La versión ofrecida al lector proviene del narrador o de la visión subjetiva del personaje? ¿Cuáles son los valores éticos que rigen el comportamiento de los protagonistas? ¿Qué relación guardan dichos valores con el escenario descrito? Si empezamos por considerar la narración desde el punto de vista costumbrista, es posible detectar el ojo crítico de Patán con respecto a los comportamientos sociales de nuestros contemporáneos (claramente mexicanos, por cierto). En la novela, la descripción de los turistas que pasan sus vacaciones en la playa, de los cuerpos que distan tanto de los modelos idealizados de las revistas de moda y chismes que constituyen su elección de lectura, del comportamiento entre servil y condescendiente de los meseros, sitúa al lector en el rango de cotidianidad que es tema común en la obra de Patán. Sin embargo, este nivel pasa a un plano secundario cuando Gastón recibe el extraño ofrecimiento de un desconocido, Ulises, que podríamos situar en la tercera edad: hacerle el amor a la esposa, Estela, como regalo de cumpleaños y con anuencia de ésta. El ofrecimiento es, en realidad, resultado de una apuesta entre la pareja en relación con la apariencia timorata de Gastón y las posibilidades de que éste aceptara participar en "la aventura". A partir de ahí se desarrolla una trama que podríamos ubicar como 


\title{
$126 \square$ IRONÍA Y EXILIO EN LA OBRA RECIENTE DE FEDERICO PATÁN
}

comedia de enredos por el tipo de situaciones y la caracterización extrema, caricaturizada, de los personajes involucrados pero, más que eso, se inicia una sucesión de decisiones que pone en tela de juicio algunos valores socialmente aceptados.

Ante los ojos de Gastón (y en cierta forma, del lector también), el ofrecimiento y el momento mismo de la aventura (con la mujer equivocada, en una habitación equivocada) parecen salidos de "novelas baratas", pero adquieren la dimensión de una farsa o comedia negra por el grado de incongruencia con el ritmo y la naturaleza que distinguía una trama que seguía "la lógica de lo cotidiano" (126). Es en esta zona gris que se forma entre lo inocuo de la cotidianidad y lo absurdo de situaciones elegidas, al fin y al cabo, por un ser mediocre, sin muchas convicciones, donde la ironía de la novela llega al grado de lo macabro. Para Angelina Muñiz este tipo de protagonistas son representativos de un exilio interior distintivo de la condición de exilio permanente que impera en mucha de la narrativa contemporánea. Para ella, los personajes de la narrativa de Patán son

\begin{abstract}
[...] personajes leves, a la manera de Milan Kundera, cuya razón de ser es su inseguridad y su falta de una ley sustancial. Son, por lo tanto, personajes totalmente contemporáneos, reflejo del sentir general ante el desconcierto ético de la segunda mitad del siglo Xx. Personajes que han recibido una herencia fragmentada y carecen de la clave que arme las piezas del rompecabezas. Personajes que se debaten en intentos de llegar a ser, de llegar a obtener algo tangible en la vida [...] No se trata de personajes derrotados, sino de personajes en encrucijada, a punto de hallar una verdad inefable, cuyas vidas son interrumpidas porque desaparecen o se hunden aún más en su misterio (163).
\end{abstract}

En el caso de Gastón, la encrucijada surge de la necesidad de dar sentido a su vida mediante alguna aventura digna de la literatura. Sin embargo, la elección de la "aventura" dista mucho de los valores de caballerosidad de aquella película vista en la infancia, sin permiso de los padres. La confusa relación entre azar, destino y libre albedrío conduce a su vida a un punto sin retorno. De alguna manera, se confirma la predicción hecha por su amiga Norma al inicio de su relación: "Si [los seres encargados de dirigir nuestro destino] son chocarreros, acabará mal tu aventura" (46). Gastón se convierte, entonces, en una especie de marioneta que cree que dirige su vida pero que, en realidad, es incapaz de percibir y dilucidar los hilos que se mueven alrededor de su persona. El azar lo lleva a la misma ciudad costera y, en el momento climático de la novela, a la misma playa donde está Norma, pero su miopía existencial le impide tomar conciencia de las consecuencias reales de sus actos.

Si el título mismo de la novela sugiere que el paraíso no existe, la obsesión de los personajes por encontrarlo se convierte en una búsqueda fútil. Sea el paraíso un escenario soñado, una vida idealizada - muchas veces en términos literarios - o una condición mental, éste parece sólo existir en la mente de los personajes o en las conversaciones de sobremesa en las que las disquisiciones tienen un toque filosófico. Al igual que los diálogos clásicos o renacentistas, un viejo encarna varias virtudes que los más jóvenes no alcanzan a entender. El amor, las relaciones de pareja, la soledad, la solidaridad con el 
prójimo son discutidos y desgranados con diversos matices de seriedad o cinismo. El caso de Benito, el viudo que lleva su soledad con la dignidad que le otorga haber llevado una vida relativamente feliz y bien avenida con Matilde, su mujer, sólo es entendido por Norma, quien ha elegido una soledad placentera en su rutina. Para ellos los paraísos "se dan en una versión modesta, cuando aceptas como paraíso lo cotidiano" (199).

Sin embargo, la informalidad elegante y respetuosa de Benito parece ser cosa del pasado, encarnación de valores que gradualmente van dejando de existir. Su opuesto lo constituyen, por supuesto, Ulises, personaje grosero cuya proposición indecorosa sitúa a Gastón como un protagonista antiheroico e insignificante, y Fausto, parodia del macho mexicano que ni siquiera alcanza a representar su rol de Otelo. A diferencia de Fulgencio que en La ceremonia perfecta (1994) encarna una maldad mezquina, el ofrecimiento de Ulises carece de resortes ulteriores salvo comprobar, junto con su mujer Estela, hasta dónde llegan los límites éticos de un personaje mediocre y aburrido como Gastón. Sin embargo, en una coincidencia que lleva al extremo los límites de verosimilitud de la novela, Mirta escucha la conversación y decide intervenir para participar ella también en la aventura. El hecho de que Gastón olvida el número de cuarto lo lleva a los brazos de Mirta en lugar de los de Estela. Sin percatarse de su equivocación, cumple sus tareas sexuales con aptitud sólo para encontrarse con que ha sido observado todo el tiempo por la pareja (¿marido?) de Mirta, Fausto, quien al ver ofendido su honor lo amenaza de muerte con un arma. La escena, digna de una comedia negra por lo absurdo de la situación, la vulgaridad de Mirta y Fausto, y la torpe ignorancia de Gastón, confirma la vacuidad de un entorno en el que los lazos afectivos parecen haber desaparecido. A partir de aquí, la novela toma el giro paródico de thriller policiaco o novela negra en la que falta el personaje principal: el detective o policía que aclarará la situación. En cambio, tenemos una situación en la que Gastón pierde, por así decirlo, la inocencia y, por tanto, la posibilidad de encontrar su paraíso. Su decisión de aceptar la propuesta, que para él "[s]onaba a destino manifiesto y la acepté porque me sentí personaje griego" (95) no hace más que reducir ante los ojos del lector la humanidad del protagonista, quien a falta de una hibrisy una hamartia genuinas queda representado en su mediocridad.

Lo anterior, aunado al súbito cambio de perspectiva narrativa que mantiene en suspenso el desenlace de lo ocurrido en la habitación del hotel, convierte a Gastón en criminal e inocente, en perseguido y detective al mismo tiempo. En medio de los extremos, y ante la ambigüedad que resulta del desconocimiento real de los hechos, surge la encrucijada moral y ética que él tendría que resolver: ¿qué ocurrió verdaderamente en la habitación cuando él salió?, ¿deberá aclarar todo ante la policía para exculpar al inocente que ha sido detenido por equivocación?, ¿contribuir a una muerte lo convierte a uno automáticamente en asesino?, ¿incluso, como le aconteció a él, cuando se ayuda a bien morir a un enfermo terminal?

En algunas de las sobremesas, Mario, amigo ocasional y novelista, le dice la Gastón:

No es necesario haber publicado para ser novelista. Lo de novelista es una condición mental, que con distinta frecuencia se concreta en libros [...] Ser novelista es una 


\section{$128 \square$ IRONÍA Y EXILIO EN LA OBRA RECIENTE DE FEDERICO PATÁN}

manera de ver el mundo. Los médicos tienen la suya y los políticos otra, por lo general maloliente... Ah, pues la de novelista consiste en buscarle razones a la conducta y quizá mejor a la existencia humana... (124).

A pesar de pertenecer a géneros diferentes, autobiografía, una, novela, otra, las dos obras más recientes de Federico Patán parecen negar esa posibilidad de encontrar razones a la conducta y a la existencia humana porque, a final de cuentas, dejan en el aire la posibilidad de un final aprehensible. En los recuerdos expuestos en Una infancia llamada exilio, Patán nos ofrece una sociedad en la que todavía permean lazos de solidaridad y afecto, a pesar de estar éstos matizados por un fuerte sentido de otredad. Sin embargo, la contundente desmitificación del sueño familiar de alcanzar el paraíso en la ciudad de México se filtra en la atmósfera de la obra narrativa del autor hasta alcanzar el sentido de desilusión, futilidad y arbitrariedad que caracterizan ¿Y el paraíso? Más allá de la estética y la lógica de lo cotidiano, la novela nos habla de conductas irracionales que ya no encuentran un ancla ni siquiera en los ideales literarios que contrapuntean las tramas de otras obras del autor. Patán deja al lector en una indefinición que no permite valorar siquiera la naturaleza de lo presentado. ¿Es Gastón, acaso, un héroe trágico? ¿Existe la tragedia en un entorno mezquino y mediocre? $\mathrm{O}$, quizás, el autor sólo juega con las expectativas del lector y lo coloca frente a una comedia negra en las que los valores que permiten la convivencia han desaparecido. En cualquiera de los dos casos, Federico Patán nos obliga a enfrentarnos al tema que vincula su obra creativa: la dificultad de encontrar una verdad y una felicidad que trascienda la rutina de lo cotidiano.

\section{Obras citadas}

Curcó, Carmen y Maite EzcurdiA, comps. 2009. "Identidad personal e identidad cultural: un panorama". Discurso, identidad y cultura. Perspectivas filosóficas $y$ discursivas. México: UNAM, Coordinación de Humanidades.

FreEMAN, Mark. 2010. "Telling stories. Memory and Narrative". Memory. Histories, Theories, Debates. Ed. Susannah Radstone y Bill Schwarz. Nueva York: Fordham University Press.

LÓPEZ AGUILAR, Enrique. 2012. Los poetas hispanomexicanos. Estudio y antología. México: UAM/Eón Ediciones.

MuñIz-Huberman, Angelina. 1999. El canto del peregrino. Hacia una poética del exilio. Barcelona: Gexel/unAM.

PATÁn, Federico. 2012. ¿Y el paraíso? México: Eón.

2010. Una infancia llamada exilio. México: Eón.

PAVÓn, Alfredo. 2008. "Federico Patán y la voluntad de escribir". Revista de Literatura Mexicana Contemporánea, año XIV, vol. 15, núm. 36. Pp. I-VII. 